\title{
Agricultura Familiar e Economia Solidária: a experiência da Associação MUTIRÃo, na região do Baixo Tocantins, Amazônia Paraense
}

Family Agriculture and Economy of Solidarity: the experience of the Association MUTIRÃO, in the region of Baixo Tocantins, Amazônia Paraense

\author{
Adebaro Alves dos Reis ${ }^{1}$ \\ Wagner Luiz Nascimento do Nascimento ${ }^{2}$ \\ Alciene Oliveira Felizardo ${ }^{3}$ \\ Amanda Rayana da Silva Santos ${ }^{4}$
}

Artigo recebido para publicação em jan./2015 e aceito para publicação em mai./2015

\section{RESUMO}

O presente trabalho apresenta a experiência de agricultores e agricultoras familiares que se articularam a partir do Projeto MUTIRÃO, na região do Baixo Tocantins, estado do Pará. Esses atores sociais se organizam a fim de garantir às populações ribeirinhas melhor qualidade de vida, geração de emprego e renda, além do acesso a bens fundamentais como saúde, educação, formações, assistência técnica na produção agrícola, em especial no cultivo e manejo de açaí (Euterpe oleracea Mart.) nativo. Além de estabelecer relações com outras entidades de assistência técnica, de pesquisa e de ensino, a Associação MUTIRÃO viabilizou o surgimento de novas formas organizacionais no município: a Cooperativa Agrícola dos Empreendimentos Populares de Igarapé Miri - CAEPIM, a Cooperativa de Desenvolvimento do Município de Igarapé Miri - CODEMI e a Associação de Mulheres de Igarapé Miri - ASMIM.

Palavras-chave: Organização social. Várzea. Desenvolvimento territorial. Agricultura familiar. Amazônia.

\section{ABSTRACT}

This study shows the experience of family farmers that were articulated from the joint effort Project in the Baixo Tocantins, Pará State. These social actors are organized to ensure the riverside communities better quality of life, generate jobs and income, and access to basic goods such as health, education, training, technical assistance in agricultural production, especially in the cultivation and management of açaí (Euterpe oleracea Mart.). In addition to establishing relationships with other service organizations, research and teaching, the Association task force contributed to the emergence of new organizational forms in the city: the Agricultural Cooperative of Popular of Igarapé Miri (CAEPIM), the Development Cooperative of Igarapé Miri (CODEMI) and the Women's Association of Igarapé Miri (ASMIM).

\footnotetext{
${ }^{1}$ Economista, Msc. em Planejamento do Desenvolvimento e Doutor em Desenvolvimento Sustentável do Tópico Úmido pela Universidade Federal do Pará/Núcleo de Altos Estudos Amazônicos - NAEA, Professor do Instituto Federal de Educação, Ciência e Tecnologia do Pará - Campus Castanhal, Pará. adebaroreis@yahoo.com.br

${ }^{2}$ Graduação em Engenharia Agronômica pelo Instituto Federal de Educação do Pará - Campus Castanhal, Pará, bolsista da Incubadora Tecnológica de Desenvolvimento e Inovação de Cooperativas e Empreendimentos Solidários - INCUBITEC. wagnerlnnascimento@gmail.com

${ }^{3}$ Graduação em Engenharia Agronômica pelo Instituto Federal de Educação do Pará - Campus Castanhal, Pará, bolsista da Incubadora Tecnológica de Desenvolvimento e Inovação de Cooperativas e Empreendimentos Solidários - INCUBITEC. alcifelizardo@yahoo.com.br

${ }^{4}$ Graduação em Engenharia Agronômica pelo Instituto Federal de Educação do Pará - Campus Castanhal, Pará, bolsista da Incubadora Tecnológica de Desenvolvimento e Inovação de Cooperativas e Empreendimentos Solidários - INCUBITEC. santtos.agro@gmail.com
} 
Revista Tecnologia e Sociedade, Curitiba, v. 11, n. 22, 2015

Edição Especial XII Encontro Nacional de Engenharia e Desenvolvimento Social

ISSN (versão online): 1984-3526

ISSN (versão impressa): 1809-0044

Key words: Social Organization. Floodplains. Territorial Development. Family Agriculture. Amazon.

\section{INTRODUÇÃO}

A economia capitalista tem gerado desigualdades socais e regionais como consequência da divisão internacional do trabalho, fazendo surgir formas de trabalho precarizadas, intermitentes, parcelares, terceirizadas e análogas à escravidão nos mais diversos espaços da produção. No entanto, no campo da resistência aos efeitos da exploração capitalista do trabalho, vem se construindo uma alternativa concreta, a partir da experiência dos próprios trabalhadores e seus movimentos sociais de contraposição à degradação da vida.

Um dos exemplos, de resistência mostra-se pela economia solidária, que se torna estratégica na acumulação de forças frente ao modo de produção capitalista, como afirma Barbosa (2011). Assim, entende-se que a economia solidária tem por princípio básico se contrapor à exploração da força de trabalho ao propor processos de produção cooperada, livremente associada e sob o controle dos próprios trabalhadores, além da propriedade coletiva dos meios de produção e a divisão equitativo dos resultados da produção (SINGER, 2002).

Assim, busca-se mostrar como a economia solidária tem contribuído para a organização sócio produtiva da agricultura familiar, em áreas de várzea da Amazônia brasileira. Neste espaço, a Associação Mutirão, na região do Baixo Tocantins, tem se colocado como um sujeito coletivo essencial para a melhoria da qualidade de vida de seus cooperados, mas também de uma rede de empreendimentos solidários, cuja mobilização produtiva se constitui como elemento central do desenvolvimento territorial rural. A cooperação e não a competição é o eixo dessa dinâmica socioeconômica espacial.

A Associação Mutirão de Igarapé Miri, surgiu nos anos 90, como um processo de organização de agricultores familiares a fim de garantir melhoria de qualidade de vida às populações ribeirinhas, gerando postos de trabalho, acesso à renda e à equipamentos coletivos essenciais para a produção e reprodução, com base no trabalho associado. 
Revista Tecnologia e Sociedade, Curitiba, v. 11, n. 22, 2015

Edição Especial XII Encontro Nacional de Engenharia e Desenvolvimento Social

ISSN (versão online): 1984-3526

ISSN (versão impressa): 1809-0044

Neste sentido, o texto resume uma experiência de pesquisa e extensão no âmbito da Incubadora Tecnológica de Desenvolvimento e Inovação de Cooperativas e Empreendimentos Solidários (INCUBITEC). Traz no primeiro item uma discussão sucinta sobre economia solidária como referência da mobilização dos territórios produtivos da agricultura familiar no Baixo Tocantins. No segundo item faz uma relação entre agricultura familiar e economia solidária, a fim de mostrar as potencialidades decorrentes dessa articulação. No terceiro, trata dos aspectos metodológicos da pesquisa participativa, na qual houve o envolvimento dos protagonistas, e; finalmente, discute o processo de organização da Associação Mutirão e sua importância na articulação de uma rede de empreendimentos solidários e suas alianças em busca da melhoria da qualidade de vida no território do Baixo Tocantins, sob a perspectiva do associativismo e da economia solidária.

\section{CONTRIBUIÇÕES TEÓRICAS SOBRE ECONOMIA SOLIDÁRIA - ECOSOL}

Autores como Cunha (2003) e Singer (2003) afirmam que a economia solidária deve muito às contribuições teóricas dos socialistas utópicos, principalmente às experiências de associação desenvolvidas na prática pelos trabalhadores, desde a época dos Pioneiros de Rochdale.

A economia solidária nasceu pouco depois do capitalismo industrial, como reação ao espantoso empobrecimento dos artesãos, provocado pela difusão das máquinas e da organização fabril da produção, conhecida como revolução industrial (SINGER, 2002). Assim, enquanto o capitalismo devora a sociedade e aponta a obtenção de lucro como objetivo principal e meta final, a economia solidária busca garantir o direito das pessoas viverem uma vida melhor e com sentido.

Para Santos (2005), a economia solidária se constituiu como uma invenção do operariado em face das sequelas do capitalismo industrial, que desde a sua origem mostrou a pobreza e o desemprego como consequência do desenvolvimento das forças produtivas associadas à ciência e a tecnologia, como a difusão das máquinas-ferramentas e do motor a vapor do século XIX. Ainda nessa linha de pensamento, Singer (2002, p. 114-115) afirma que a economia solidária foi concebida como uma alternativa superior ao capitalismo, ou seja, uma forma de produção que não se restringe à produção de coisas, mas também de sentidos, ao... 
Revista Tecnologia e Sociedade, Curitiba, v. 11, n. 22, 2015

Edição Especial XII Encontro Nacional de Engenharia e Desenvolvimento Social

ISSN (versão online): 1984-3526

ISSN (versão impressa): 1809-0044

[...] melhorar o relacionamento com familiares, amigos, vizinhos, colegas de trabalho, colegas de estudo etc.; na liberdade de cada um de escolher o trabalho que the dá mais satisfação; no direito à autonomia na atividade produtiva, de não ter de se submeter a ordens alheias, de participar plenamente das decisões que o afetam (SINGER, 2002, p. 114-115).

Esses pressupostos evidenciam a economia solidária como alternativa à economia dominante, na medida em que é vista não só como uma necessidade material, mas também como uma ferramenta de transformação social e opção ideológica (CUNHA, 2003). É válido ressaltar que os empreendimentos solidários se sustentam na contraposição à economia capitalista, essencialmente incompatível com as aspirações de existência humana saudável. "Uma contestação mais interessante ao modelo econômico capitalista, baseado na cultura do lucro e de risco ao próprio planeta ao destruir os ecossistemas, com demandas geradoras de um consumo desenfreado, particularmente de produtos descartáveis ou supérfluos" (NUNES, 2009). Assim, a economia solidária se efetiva como uma fonte teórica e prática de contestação do capitalismo.

Razeto (apud GADOTTI; GUTIÉRREZ, 1999) ressalta que a economia solidária é uma forma de produção associada, envolvendo pessoas na construção de um mundo mais solidário, ético e sustentável. Nestes termos, o autor associa a economia solidária ao desenvolvimento sustentável, na medida em que introduz o sonho do bem viver, com uma proposição dinâmica entre homem e natureza. Sob essa compreensão, os empreendimentos de economia solidária estão diametralmente opostos aos empreendimentos capitalistas. A gestão democrática torna-se o grande marco de separação das relações despóticas do capitalismo.

Segundo Souza (2012), outro aspecto fundamental da economia solidária e de natureza institucional implicado no desafio da construção de sua identidade na relação com outros movimentos sociais, a exemplo da agricultura familiar, bem como, na definição de sua posição na estrutura do estado brasileiro.

A economia solidária, nesse sentido, traz um novo sentido ao avançar na construção de redes de desenvolvimento territorial solidário, abrangendo as dimensões econômica, social, cultural e ambiental sob uma mesma unidade, apresentando-se como um patamar superior para análise de análise de experiências concretas. 


\section{AGRICULTURA FAMILIAR E ECOSOL}

A agricultura é uma das atividades humanas que mais impactam os ecossistemas em que vivemos, fazendo-se necessário analisar esses impactos sob a ótica do desenvolvimento rural sustentável (DAL SOGLIO, 2013). Os efeitos da agricultura foram se agravando ao longo da história, tornando-se predatórios aos ecossistemas. Segundo Van de Ploeg (2008), esse fenômeno ocorreu a partir do momento em que o "lucro" passou a ser o principal objetivo da agricultura, reduzindo a produção de alimentos à segundo plano, enquanto produtos essenciais à sociedade.

Segundo Wanderley (2001), a agricultura familiar não é uma categoria social recente na medida em que tem garantido a produção de alimentos; também não corresponde a uma categoria analítica nova na sociologia rural. Embora sua utilização, com o significado e abrangência que lhe fora atribuído nos últimos anos, no Brasil, lhe conferem aspectos de novidade e renovação.

Para Caporal e Costabeber (2000), a agricultura familiar é, ao mesmo tempo, unidade de produção, de consumo e de reprodução, que funciona mediante uma lógica de produção combinada de valores de uso e de valores de troca. Uma unidade indissolúvel que se constitui a partir de relações sociais articuladas à natureza e ao meio ambiente, como condições essenciais articuladas em face ao vínculo com a terra.

Nesta mesma direção Ploeg (2006) pensa a agricultura camponesa como um campo de estreita relação social com a produção, definindo-a por meio de seis características: a primeira mostra a produção associada à natureza; a segunda diz respeito a autogestão da unidade produtiva, tendo em vista que estes são os próprios gestores de seus meios de produção (terra, fertilidade, trabalho, capital); a terceira, constitui-se pela relação diferenciada e diversificada com mercados, sob certa autonomia; a quarta, evidencia que as condições anteriores gera a própria manutenção de sua condição, para a produção e reprodução da unidade familiar; a quinta confere ao processo plural das atividades desenvolvidas no interior desse tipo de estabelecimento e, finalmente; a necessária relação de cooperação e reciprocidade neste ambiente. 
Revista Tecnologia e Sociedade, Curitiba, v. 11, n. 22, 2015

Edição Especial XII Encontro Nacional de Engenharia e Desenvolvimento Social

ISSN (versão online): 1984-3526

ISSN (versão impressa): 1809-0044

A agricultura familiar sob essa perspectiva revela-se como uma atividade diversificada e heterogênea, mas que mantém traços comuns no que se refere a utilização dos recursos naturais, com o uso intensivo do trabalho e, por vezes, da ajuda mútua. Essas condições, segundo Ploeg (2006), caracterizam-se por regras diferenciadas do mercado capitalista.

Assim, a agricultura é mais que um complicado novelo entretecido onde os fios (solo, plantas, animais, implementos, trabalhadores, matéria prima, influências ambientais) são sustentados e construídos pelo agricultor, que forma um núcleo de alocação, produção e consumo de recursos, em que o grupo familiar organiza-se de modo autônomo, ligados através de laços de sangue, amizades, histórias, tradições e controle coletivo do território. Suas relações econômicas, sociais e políticas influenciam o sistema de produção no estabelecimento agrícola, servindo para atenuar os riscos recorrentes de objetivos mal sucedidos, a fim de valorar práticas sustentáveis (UHLMANN, 2002).

A sustentabilidade está, ainda, associada à viabilidade e à longevidade. Incorpora, neste caso, a ideia de um processo dinâmico e durável e, além do crescimento econômico, um caráter de justiça social, de preservação das culturas locais e de recuperação e preservação ambiental. Dentro de uma harmonia homem-natureza, o desenvolvimento sustentável deve, ao mesmo tempo, oportunizar, em cada local, o crescimento da economia a curto, médio e longo prazos, a geração de postos de trabalho com distribuição mais equitativa de renda, respeitando culturas locais e reconstruindo e/ou preservando o equilíbrio ambiental. Com base na diversidade de situações e de soluções, o desenvolvimento toma um teor próprio em cada realidade local (ALMEIDA apud PREZOTTO, 2002, p.52-53)

Corroborando com a ideia de que os agricultores familiares encontram alternativas para favorecer suas atividades políticas, econômicas e sociais, vê-se a organização social como substrato dos empreendimentos econômicos solidários, ao criar espaços estratégicos no enfrentamento das sequelas da sociedade capitalista e ao garantindo-Ihes acesso a direitos sociais para seus associados e para o território ao qual estão inseridos (LAVILLE; FRANÇA FILHO, 2004). Nestes termos, compreende-se que as iniciativas de base econômica solidária, trabalho associado e autogestionário configuram recurso capazes de acumular forças na transição de um modelo socioeconômico pautado pela exploração para um modelo circunscrito a 
Revista Tecnologia e Sociedade, Curitiba, v. 11, n. 22, 2015

Edição Especial XII Encontro Nacional de Engenharia e Desenvolvimento Social

ISSN (versão online): 1984-3526

ISSN (versão impressa): 1809-0044

economia dos trabalhadores livremente associados (VIEITEZ; DAL RI, 2008); (TIRIBA, 2008).

Por essas razões, a economia solidária tem se mostrado importante na agricultura familiar, pois favorece 0 acesso a bens e serviços que individualmente seria impossível de captar. Suas ações nascem no campo das lutas de resistência, predominantemente, por meio de reivindicações de trabalhadores e trabalhadoras excluídos do mercado de trabalho e com direitos violados.

Das características da economia solidária, a autogestão é a mais comum delas, a qual, segundo Singer (2000), pode ser compreendida como uma forma de promoção da democracia em instituições sociais em que trabalhadores são os sócios.

Araújo et. al. (2007), nessa linha de raciocínio, ressaltam que os princípios norteadores da transformação da agricultura familiar se alinham ao associativismo e à participação social. Afirmam ainda que as comunidades se organizam para resolver necessidades comuns, que influenciam na melhoria das condições de vida dos mesmos. Pensa-se a economia solidária como base dessa organização sócio produtiva, com níveis mais elevados de participação, autonomia e autopromoção dos trabalhadores. Portanto, um esforço coletivo na solução de problemas comuns ao grupo, com respostas coletivas (GONZALEZ, 1995).

A economia solidária mostra-se como uma prática social que articula economia, política e sociedade sob uma totalidade aberta e pautada na mobilização de trabalhadores dos mais diferentes ramos de atividades produtivas e de serviços. Essa prática possibilita acumular forças para o que Rosa Luxemburgo identifica como o poder das massas, que agindo de forma coletiva aprende a se autogerir.

Assim, a economia solidária torna-se um exercício concreto desse agir coletivo na construção de um projeto de sociedade, na medida em que porta valores importante sobre o meio ambiente, a igualdade, a justiça social, a autogestão e a democracia, pilares essenciais na ultrapassagem do individualismo possessivo. A economia solidária retoma práticas coletivas de organização do trabalho e da produção, particularmente quando alçadas nas experiências agroecológicas, de soberania e segurança alimentar, na construção de uma sociedade em que a centralidade seja a sustentabilidade humana em sintonia com a natureza (SENAES, 2004; 2007). 


\section{REGIÃO DO BAIXO TOCANTINS - LOCAL DE PESQUISA}

O município de Igarapé Miri, região do Baixo Tocantins, estado do Pará, constitui-se como universo da pesquisa; o qual caracterizado por altas precipitações pluviométricas e por influências das marés nas áreas de várzea. Dos quase 500 mil habitantes dos nove municípios, que formam essa microrregião do estado, cerca de 150 mil vivem diretamente na beira dos rios e igarapés, conhecidos como ribeirinhos e ribeirinhas.

Essa configuração geofísica mostra-se compõem um território com áreas de várzea (ilhas) e terras firmes, caracterizadas por uma extensa relação da população com o meio natural (CARDOSO et al.2007), portanto, espaços continentais e ilhas, condição essa que possibilita uma produção diversificada em face da própria natureza. $\mathrm{Na}$ região de ilhas a população constitui um modo de vida particular, ou seja, o modo de vida ribeirinho (Figura 1 -a), devido a dependentes da acessibilidade fluvial (Figura 1 -b). As famílias ribeirinhas, em sua maioria, vivem do extrativismo animal e vegetal, tendo na pesca (Figura 2 - a) e da coleta do fruto do açaí (Figura 2 - b).

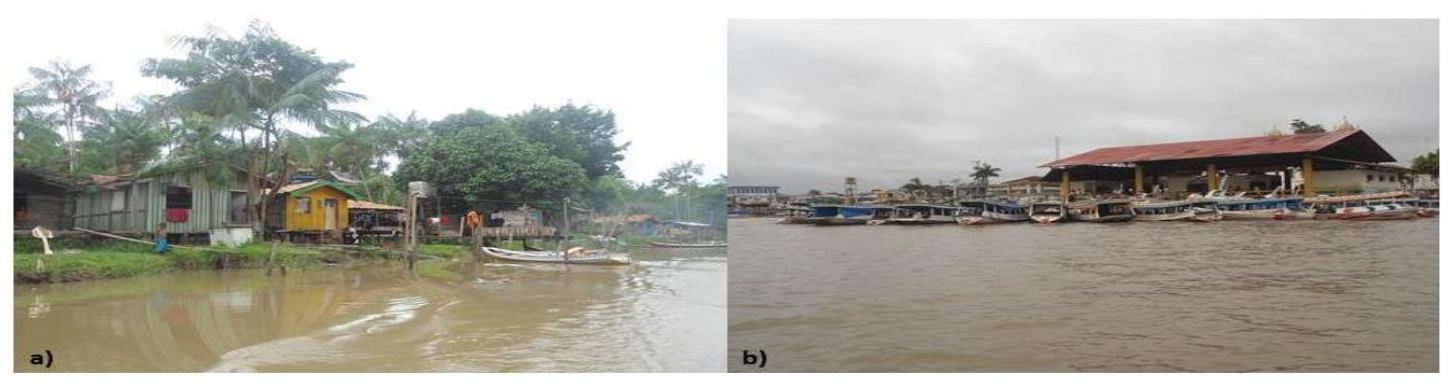

Figura 1 - a) Representa as principais formas de moradias na área de várzea, caracterizada por casas sobre as águas do rio, elevadas com pisos do tipo palafitas; b) Visão da chegada ao porto do município de Igarapé Miri, onde dezenas de embarcações ficam "estacionadas", enquanto seus proprietários realizam o comércio na cidade. Fonte: Própria dos autores (2014).

Nas ilhas predomina o extrativismo de culturas como açaí, palmito (extraído da estirpe da palmeira do açaizeiro), andiroba (Carapa guianensis A.), cacau (Passiflora cacao), além do extrativismo animal com a caça e a pesca, a última com maior incidência. Ao longo dos anos, a região do Baixo Tocantins vem sofrendo inúmeras mudanças em sua dinâmica produtiva e social. Essa região apresenta potencial de desenvolvimento com práticas sustentáveis devido à riqueza natural, embora ainda seja mobilizada, em grande medida, como exportadora de matéria 
prima. Neste aspecto, os governos municipal e estadual têm desenhado inúmeros planos de desenvolvimento, mas sem efetividade prática na medida em que não há alocação de ações de políticas públicas, em especial, na área de infraestrutura. Um espaço público de conflitos e entraves, que Corrêa (2012) afirma ser uma notória ausência da intervenção do Estado na região.

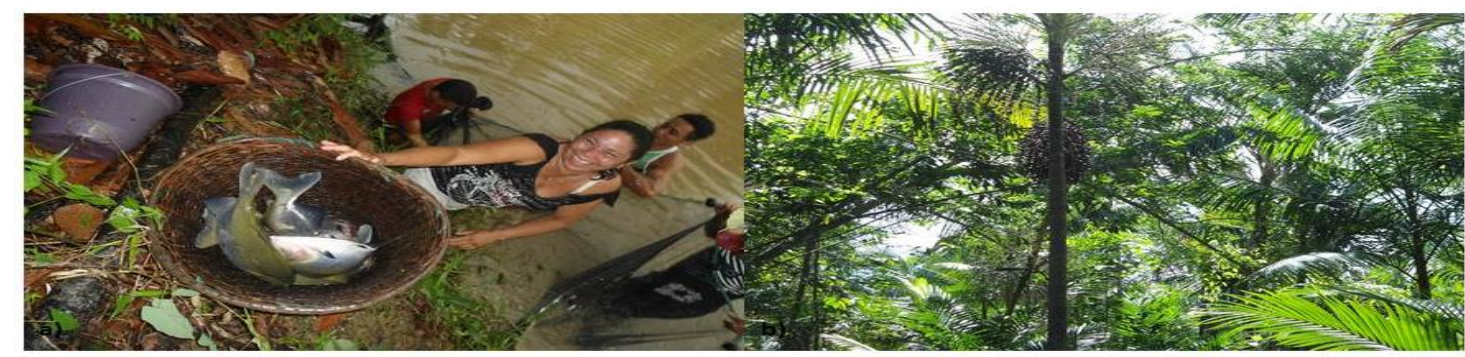

Figura 2 - a) Mostra agricultores familiares realizando o extrativismo animal característico da região, a pesca; e b) Apresenta a árvore do açaí (Euterpe oleracea Mart.), principal fonte de alimentação e renda da região. Fonte: Própria dos autores (2014).

\section{A PESQUISA PARTICIPATIVA PARA UMA AÇÃO ENGAJADA}

A pesquisa participativa tem como eixo a relação dialógica entre pesquisadores e pesquisados, proporcionando a troca de conhecimentos entre os grupos em interação, sejam as áreas de conhecimento dos pesquisadores integrantes da Incubadora Tecnológica de Desenvolvimento e Inovação de Cooperativas e Empreendimentos Solidários (INCUBITEC), como economistas, administradores, tecnólogos em aquicultura, tecnólogos em agroecologia entre outros, seja os ribeirinhos envolvidos na pesquisa, na medida em que seus empreendimentos constituem parte e força motriz do processo de incubação.

Trata-se, portanto, de uma relação de confiança entre pesquisadores e sujeitos pesquisados, a partir de um envolvimento entre as duas partes constitutivas da unidade epistemológica da pesquisa, uma realidade do tipo participativo/coletivo, em que há consciência das atividades teórico-práticas encaminhadas. Gil (2001) ressalta a participação como um elemento explicitado no processo de conhecimento e articulado pela reciprocidade/complementaridade entre os grupos implicados, devido ao fato de ter algo a "dizer e a fazer". "Não se trata de um simples levantamento de dados". A metodologia participativa mostra-se no engajamento das equipes em processos de estudos teóricos e envolvimento prático na formação e assessoria técnica. 
Revista Tecnologia e Sociedade, Curitiba, v. 11, n. 22, 2015

Edição Especial XII Encontro Nacional de Engenharia e Desenvolvimento Social

ISSN (versão online): 1984-3526

ISSN (versão impressa): 1809-0044

Neste sentido, a pesquisa não corresponde a um tipo tradicional-normativo, mas uma ação realizada em estreita cooperação entre pesquisadores e sujeitos protagonistas da associação, a fim de solucionarem problemas coletivos, em relação ao manejo e à aquicultura, momentos que possibilitaram o envolvimento dos grupos em processos de interação, tanto na identificação, na análise e nas soluções encontradas, uma realidade investigada de modo cooperativo e participativo, como pressupõe Thiollent (2005).

O autor reforça a importância de se "definir com precisão, qual ação, quais agentes, seus objetivos e obstáculos, qual exigência de conhecimento a ser produzido em função dos problemas encontrados na ação ou entre os atores da situação" (THIOLLENT, 1985).

Como o objetivo do trabalho é apresentar a experiência de agricultores e agricultoras familiares que se articularam a partir do Projeto MUTIRÃO, os pesquisadores buscaram dialogar com o quadro social da Associação MUTIRÃO, a fim de captar o máximo possível de informações, mas, além disso, compreender quais as fragilidades e necessidades encontradas no empreendimento solidário.

Desta forma, houve um contato inicial com a comunidade, membros do empreendimento MUTIRÃO, tanto com os diretores, quanto com o quadro social que seria atendido e/ou em estudo, por meio das ações de incubação em face dos resultados obtidos. Assim, os primeiros contados foram dedicados à verificação das demandas, necessidades, fragilidades, mas também para compreender as potencialidades do empreendimento, nos encaminhamentos das ações de desenvolvimento/fortalecimento da própria comunidade. Com base nesses levantamentos e observações realizou-se, no âmbito específico do grupo de pesquisadores, um planejamento em relação às ações demandadas pelos atores sociais, e ainda, um estudo sobre as principais ferramentas para a execução das atividades demandadas, portanto, para alcançar os resultados esperados.

A pesquisa participativa, portanto, possibilitou uma ação que é ao mesmo tempo de conhecimento e de intervenção na relação direta com os trabalhadores da agricultura familiar associados, com momentos de avaliação e adequação das ferramentas. Essa (re)estruturação/adequação, ocorreu em virtude do meio biofísico em que se encontra a população das áreas de várzeas, com suas especificidades, onde determinadas técnicas de produção e manejo não se aplicam ao regime das 
Revista Tecnologia e Sociedade, Curitiba, v. 11, n. 22, 2015

Edição Especial XII Encontro Nacional de Engenharia e Desenvolvimento Social

ISSN (versão online): 1984-3526

ISSN (versão impressa): 1809-0044

águas. Isto ocorre porque aprende-se, no Instituto, de um modo geral, trabalhar em áreas de terra firme. Assim, a convivência com as populações ribeirinha leva-nos a novos aprendizados, com a troca de conhecimentos científicos e saberes populares. Nessa realidade, "a participação da população (sujeito da pesquisa) como agente ativo no conhecimento de sua própria realidade possibilita a mesma adquirir conhecimentos necessários para resolver problemas e satisfazer necessidades. [...]. O modo de fazer o estudo, o conhecimento da realidade já é ação; ação de organização, de mobilização, sensibilização e de conscientização" (GIL, 2001).

Neste sentido, descreve-se como essa atividade se desenvolveu no território do Baixo Tocantins que, embora abranja nove municípios (MODESTO JÚNIOR; ALVES 2009) - Abaetetuba, Acará, Baião, Barcarena, Cametá, Moju, Tailândia, Baião, Oeiras do Pará, Limoeiro do Ajuru, Mocajuba e Igarapé Miri - apenas o último constituiu o lócus da pesquisa. O mapa abaixo (Figura 3) mostra a região de várzea, base dos processos de organização nas ilhas que compõem o município de Igarapé Miri.

O estudo foi realizado a partir do empreendimento econômico solidário Associação Mutirão de Igarapé Miri (MUTIRÃO), formado por agricultores e agricultoras familiares que se organizaram buscando maior representatividade frente aos poderes públicos e privados, visando garantir qualidade de vida a seus associados, acesso a crédito/financiamentos, trabalho e renda, formação, educação, responsabilidade ambiental e saúde dentre outros serviços coletivos de uso comum, portanto, para o conjunto da sociedade local. 


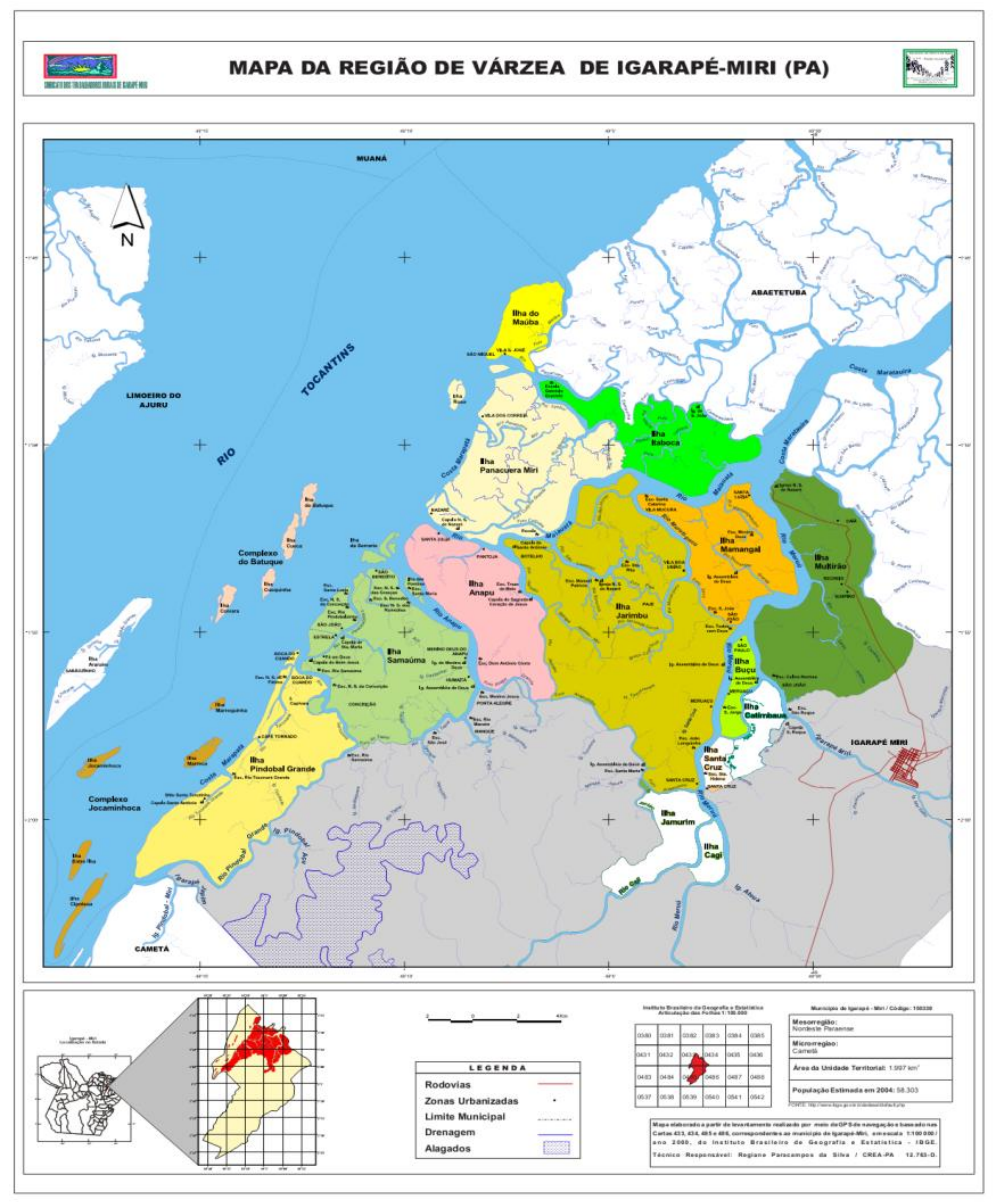

Figura 3: Mapa da região de várzea (ilhas) do município de Igarapé Miri.

Fonte: Disponibilizado pelo Sindicato de Trabalhadores e Trabalhadoras Rurais de Igarapé Miri - STTR (2014).

A pesquisa proporcionou aos pesquisadores uma experiência ímpar no aprendizado recíproco, haja vista o contato com esses atores sociais, homens e mulheres, agricultores e agricultoras familiares, possibilitaram uma troca dinâmica e rica, na medida em que os conhecimentos científicos voltados para as áreas de terra firme eram adaptados, passando por adequações no regime das águas, pois a produção em sistema de várzea requer o diálogo com os sujeitos locais, que historicamente tem gerado conhecimentos distanciados da academia, apresentando papel de suma importância para o espaço onde vivem, mas desconhecidos dos meios científicos. Neste espaço a pesquisa clássica precisa ser flexionada para captar as forma e arranjos das populações locais para lidar com esse ambiente, muitas vezes, inóspito, para aqueles que desconhecem a vida na várzea.

Os empiristas, marcados pela "ilusão objetivista", teriam dificuldade para fazer os enquadramentos dessa estreita relação entre homem e natureza. A observação direta dos fatos não é suficiente para se chegar às evidências imediatas, sem o 
Revista Tecnologia e Sociedade, Curitiba, v. 11, n. 22, 2015

Edição Especial XII Encontro Nacional de Engenharia e Desenvolvimento Social

ISSN (versão online): 1984-3526

ISSN (versão impressa): 1809-0044

auxílio de qualquer elemento subjetivo ou da ação consciente dos sujeitos ativos (HABERMAS, 1971, p. 308) e atuantes nesse espaço.

Essa ideia é reforçada por Marcuse (1968) ao afirmar que "a realidade é uma coisa muito mais rica do que aquilo que está codificado na lógica dos fatos e que, para se compreender como as coisas verdadeiramente são, torna-se necessário recusar sua simples facticidade".

Nesse sentido, buscou-se, a partir da vivência com os agricultores ribeirinhos, compreender o meio ambiente de várzea e o próprio modo de vida dos mesmos, para entender suas linguagens prenhe da relação entre homem e natureza, como um espaço amplo, dinâmico, e que passava despercebido do olhar técnico.

A sensibilidade e o diálogo mostraram-se como elementos importantes de uma aliança concreta na produção de conhecimentos e solução de problemas; as conversas e trocas de experiências apontaram para uma relação mais extensiva, na medida em que nossas formações tecnológicas mostram-se efetiva na produção de resultados concretos, o que exigem o aprofundamento de conhecimentos para o desenvolvimento de técnicas adequadas ao ambiente de várzeas.

Nesta relação com o espaço e os atores sociais, em especial, em áreas de várzea (nas ilhas de Igarapé Miri), foi possível realizar o Diagnóstico Rápido Participativo (DRP), entendido por Jardim e Pereira (2009), como "uma tentativa que visa minimizar as limitações das ciências sociais em relação ao conhecimento da realidade, especialmente, quando se envolve a realidade socioeconômica e cultural das classes populares ou de grupos sociais excluídos ou pouco inseridos na sociedade contemporânea".

A utilização do DRP em áreas de várzeas necessitou de adequações. Por exemplo, os agricultores e/ou a agricultoras não dispõem do mesmo tempo que os agricultores e/ou a agricultoras das áreas de terra firme, pois seu tempo é determinado pelo ciclo das marés, ou seja, cultivo, manejo e comercialização dependem, diretamente, do tempo das marés: se estas estão enchendo (maré lançante) ou secando (maré vazante). Então a coleta ou extração de frutos e sementes (regionais e de ocorrência endêmica) tem um período muito curto, e por essa razão os agricultores e/ou a agricultoras estão sempre chamando atenção para os períodos do dia em que as marés baixas facilitam suas atividades de coleta. Portanto, nas marés altas era o tempo das trocas de experiências, mas também de 
Revista Tecnologia e Sociedade, Curitiba, v. 11, n. 22, 2015

Edição Especial XII Encontro Nacional de Engenharia e Desenvolvimento Social

ISSN (versão online): 1984-3526

ISSN (versão impressa): 1809-0044

circulação, pois é nesses momentos que podem se deslocar nas vias fluviais, não acarretando assim, perdas para seus trabalhos.

Outra ferramenta utilizada, comumente, na realização do DRP são as caminhadas transversais nas Unidades Produtivas Familiares - UPF, quando ocorre o conhecimento efetivo das unidades produtivas, momento em que os pesquisadores buscavam reconhecer no meio biofísico, aspectos já identificados por meio das entrevistas com os proprietários das unidades. No caso da várzea, essa caminhada tornava-se mais complexa. Como está se falando de várzea, as unidades produtivas são parciais ou completamente inundadas pelo ciclo das marés, em determinados períodos do dia, dificultando assim, esse procedimento técnico. Por esse motivo, a caminhada que em terra firme leva algumas horas, em áreas de várzea podem levar dias; daí a exigência da vivência nessas unidades produtivas por um período médio de quinze dias, pois são necessários vários momentos para se reconhecer os espaços que compreendem essas unidades produtivas das famílias envolvidas na pesquisa.

Durante a caminhada transversal foi possível a coleta de dados adicionais sobre a importância de se fazer parte de um empreendimento solidário. Nesse caso, da Associação MUTIRÃO, ou ainda das vantagens e desvantagens dessa organização para o desenvolvimento familiar; a relação que existe entre a diretoria do empreendimento e o quadro social; os ganhos, até o momento, conseguidos de forma coletiva e as perspectivas para a melhoria da organização do quadro atual de sócios e para as futuras gerações.

É importante destacar que esse tipo de pesquisa agrega, como método, várias técnicas de pesquisa social, cuja diversificação possibilita a compreensão de dimensões implícitas ao mundo social e natural ao qual se imergiu no processo de pesquisa e de extensão, como pesquisador envolvido tanto no processo de coleta, quanto de análise e interpretação dos dados, além de garantir maior proximidade e interação nos processos de intervenção, na busca de resolução de problemas tanto de organização de ações, como na aplicação de técnicas e dinâmicas de grupo de cunho coletivo e interativo na produção do conhecimento e na programação da ação coletiva (GIL, 2008). 


\section{A ASSOCIAÇÃO MUTIRÃO E A CONSTRUÇÃO DE ALTERNATIVAS DA AGRICULTURA FAMILIAR SUSTENTÁVEL}

Sob esses pressupostos, observa-se as experiências dos trabalhadores do território do Baixo Tocantins, uma realidade concreta, onde as comunidades ribeirinhas organizam-se e mobilizam os territórios produtivos da agricultura familiar; suas associações e cooperativas populares, ensejando práticas coletivas, gerando acesso a bens e serviços antes inexistentes. Uma mobilização para garantir melhoria das condições de vida do conjunto dos habitantes deste território, em particular, dos associados dos diferentes empreendimentos solidários que atuam em rede de cooperação.

O movimento de resistência dos agricultores familiares ribeirinhos aos processos de exploração dos grandes latifundiários, no município de Igarapé Miri, levaram os trabalhadores, a partir dos meados dos anos 80, a perceber a importância do Sindicato dos Trabalhadores e Trabalhadoras Rurais de Igarapé Miri - STTR. A tomada deste sindicato levou-os a uma nova postura frente as questões do campo. Enquanto sujeito político, passaram a incentivar a organização social, com o objetivo de fortalecer a agricultura familiar, em busca do desenvolvimento local e territorial.

O STTR de Igarapé Miri, com o auxílio de instituições de apoio e colaboradores, introduziu o debate sobre a produção e comercialização de produtos oriundos das Unidades Produtivas Familiares - UPF de seus associados.

Esses debates e discussões intensificou a necessidade de organizar os agricultores e agricultoras da região, cujo resultado foi a construção da Associação Mutirão de Igarapé Miri, em 20 de Maio de 1990, formada por 64 sócios, na região de Ponta Negra, no rio Meruú Açu.

Essa organização teve como um de seus objetivos, acessar linhas de crédito para financiar as Unidades Produtivas Familiares (UPF) de seus associados. Desta forma, o primeiro projeto acessado pela MUTIRÃO ocorreu via o Fundo Constitucional do Norte - FNO Especial, em 1993; sendo que dos 64 sócios, apenas 27 obtiveram crédito para investimentos de suas UPF, visando o manejo, implantação e produção de açaí, constituindo-se como os primeiros financiamentos do FNO Especial para agricultores familiares do município de Igarapé Miri. 
Revista Tecnologia e Sociedade, Curitiba, v. 11, n. 22, 2015

Edição Especial XII Encontro Nacional de Engenharia e Desenvolvimento Social

ISSN (versão online): 1984-3526

ISSN (versão impressa): 1809-0044

Esses financiamentos foram obtidos com o aval da Associação MUTIRÃO, sendo a primeira experiência com o cultivo do açaí, pois a maioria dessa população vivia do extrativismo. Até então, não viam a necessidade cultivar o açaí, devido à grande ocorrência deste fruto no local. No entanto, com a elevação da demanda, a produção da região tornou-se pequena.

Assim, A Associação Mutirão buscou apoio da Empresa de Assistência Técnica e Extensão Rural (Emater), para assistência técnica aos agricultores associados. A Emater, na época, orientou para a retirada do açaí nativo, "limpando" a área desse tipo cultivo, para que houvesse um novo plantio. Segundo os técnicos, esse procedimento visava adequar o espaçamento entre os pés de açaí, adubação, entre outras formas de cultivo e manejo. Algo que chamou a atenção, não foi o fato de se retirar as palmeiras do açaí nativos, mas compreender o porquê de se retirar essas palmeiras, já que, posteriormente, as novas mudas eram da mesma variedade daquelas retiradas.

Neste aspecto os agricultores relataram que os técnicos não haviam dito que utilizariam a mesma variedade, e que mais de $50 \%$ do recurso financiado era para aquisição de adubo. Ressalta-se, no entanto, que não havia necessidade de aquisição de adubo, já que a região é fértil, devido ao sistema de inundação das marés, havendo com isso, fertilização natural do solo.

$\mathrm{Na}$ realidade, trata-se de uma orientação de imposição de pacotes tecnológicos implicados na chamada "Revolução Verde", a qual impõe, à produção agrícola, seja em que área for, a "incorporação de pacotes tecnológicos de suposta aplicação universal, que visavam a maximização dos rendimentos dos cultivos em distintas situações ecológicas" (MATOS, 2010, p. 1-2), com a introdução de agrotóxicos e fertilizantes em áreas de várzeas, extremamente vulneráveis do ponto de vista da difusão desses agroquímicos, causando sérios riscos à saúde humana, de plantas e animais que vivem em sistema das águas.

Assim, a difusão das técnicas de pesquisa agrícola em áreas sensíveis, como as várzeas, mostra a irresponsabilidade de técnicos e de órgãos financiadores, na medida em que impõe a implantação de pacotes fechados, como o uso inadequado de produtos químicos de modo homogeneizado, para as mais variadas áreas de produção agrícola, com efeitos perversos dessas práticas agronômicas e de insumos industriais. 
Revista Tecnologia e Sociedade, Curitiba, v. 11, n. 22, 2015

Edição Especial XII Encontro Nacional de Engenharia e Desenvolvimento Social

ISSN (versão online): 1984-3526

ISSN (versão impressa): 1809-0044

Ressalta-se que essa prática, "imposta" pela Emater, fazia parte do pacote dos recursos, liberados em parcelas. Portanto, era necessária uma vistoria técnica, logo, se os agricultores não seguissem as orientações, ou seja, o uso de agroquímicos, o recurso era "travado" e o agricultor não mais o acessava. Esse mesmo tipo de financiamento ocorreu com a AMAFRUTA, voltado para o cultivo de laranja e de coco, tendo como agravante que no momento da colheita não havia garantia da compra por parte desta, que havia incentivado a plantação.

Assim, observa-se falta de diálogo e de compromisso técnico, no exercício de suas atividades, tendo em vista a não observância das especificidades de cada área agrícola, repercutindo em uma ação acrítica, uma vez que estes tinham como única meta a elevação da produtividade agrícola, mantendo uma a relação formal e objetificada com os agricultores e agricultoras.

Esse tipo de assistência técnica prejudicou consideravelmente os agricultores, que por essa razão não foram capazes cumprir com o pagamento dos financiamentos junto ao FNO Especial. A orientação dos técnicos da Emater mostrou-se desarticulada da realidade da produção em área de várzea. Nesse sentido, a modernização tecnológica aplicada à produção de açaí, com uso de defensivos agrícolas e excessivo manejo dos açaizais, trouxe problemas não somente de riscos ao meio ambiente, como também deixou os agricultores sem sua principal fonte de renda.

A inadimplência dos ribeirinhos, deveu-se, em grande medida, ao tempo médio de cinco a seis anos para a coleta dos frutos dos açaizeiros, deixando-os sem renda familiar. Esse tipo de assistência técnica mostra como o chamado saber técnico profissional do agrônomo se sobrepôs ao conhecimento dos agricultores familiares, que embora inadequado, pois estes desconheciam as técnicas de cultivo e de manejo do açaí; enquanto os conhecimentos ancestrais dos agricultores ribeirinhos, sobre a coleta deste fruto peculiar de sua dieta alimentar diária não era considerada.

A crítica da revolução verde, nesse sentido, enseja novos processos de pesquisa e assistência técnica na relação direta com os agricultores familiares, como os praticados pela INCUBITEC, que vem buscando conhecer a realidade desses agricultores, a partir de suas experiências práticas, para a partir de então, trabalhar técnicas que possam favorecer a agricultura sustentável. Assim, o conhecimento das 
Revista Tecnologia e Sociedade, Curitiba, v. 11, n. 22, 2015

Edição Especial XII Encontro Nacional de Engenharia e Desenvolvimento Social

ISSN (versão online): 1984-3526

ISSN (versão impressa): 1809-0044

tecnologias sociais implementadas pelos agricultores ribeirinhos contribui para 0 aprendizado grupo de pesquisadores, com vistas à sustentabilidade dos sistemas de produção e à viabilidade na geração de renda destes produtores.

A articulação desses atores sociais via Associação MUTIRÃO, com centros de pesquisa e as instituições de formação profissional tem possibilitado uma nova realidade, como o acesso ao crédito rural e financiamento desde 1991, quando houve a aprovação do projeto intitulado MUTIRÃO, com recurso no valor de U\$\$ 124.000,00 (Cento e vinte quatro mil dólares), de uma entidade católica italiana MANITESE. Este recurso a fundo perdido, garantiu, de forma autogestionária, equipar essa associação com infraestrutura e iniciar a implementação de práticas de agricultura sustentável.

Uma parte desse recursos foi utilizado para adquirirem uma propriedade coletiva, com 540 hectares, na qual implantaram os primeiros cultivos de açaí, e onde está sediada a Associação MUTIRÃO. Na época de implantação dos primeiros cultivos de açaí, a Associação MUTIRÃO chegou a ter 240 famílias no seu quadro social.

Nesta área, realizam atividades de formação, além de se constituir como laboratório para testes de técnicas de manejo e arranjos diferenciados de plantio, para posteriormente serem replicados em suas UPF. Também há um Centro de Formação específico, intitulado Roberto Remigi. Neste Centro, há um depósito para o armazenamento da produção, uma Casa Familiar Rural, dormitórios e uma Casa para o Administrador Local. Além dessa infraestrutura, são disponibilizados barcos para transportar os associados até a sede da associação nos dias de mutirão e/ou atividades coletivas, assim como, para transportar a produção dos associados.

Com o processo de formação vinculado ao projeto MUTIRÃO, os agricultores articulados perceberam a crescente demanda por açaí in natura no mercado local, regional, nacional e até mesmo internacional. E passaram a investir em áreas de cultivo de açaí. Todo o processo de organização da produção e comercialização é discutido e aprovado em assembleia da Associação MUTIRÃO.

A diretoria da MUTIRÃO afirmou que esse processo de desenvolvimento é realizado de forma gradativamente na área comum - "área experimental", como é chamada. Neste espaço, o quadro social realiza as atividades práticas, demandadas pelos cursos e formações, com o objetivo de tornar-se uma unidade de referência. 
Revista Tecnologia e Sociedade, Curitiba, v. 11, n. 22, 2015

Edição Especial XII Encontro Nacional de Engenharia e Desenvolvimento Social

ISSN (versão online): 1984-3526

ISSN (versão impressa): 1809-0044

Uma das ações prioritária de formação está relacionada ao manejo dos açaizais nativos, que tem garantido, ao quadro social da MUTIRÃO, a capacidade de manejar adequadamente seus cultivos, com aumento da produtividade, sem prejudicar o meio ambiente, diferentemente da experiência realizada pela Emater e pela AMAFRUTAS.

O aprendizado em relação a assistência descontextualizada da sazonalidade de várzea tem possibilitado novas técnicas de manejo, com a produção de palmito, extraído da estirpe dos açaizeiros mais altos, pois, dependendo da altura da planta, esta dificulta a colheita do fruto do açaí, assim, estes são descartados para a coleta do fruto, e suas folhas, galhos estirpes etc. servem de adubo, no processo de ciclagem de seus nutrientes.

Foi possível perceber avanços na agricultura familiar, com as ações da Associação MUTIRÃO de Igarapé Miri. Um importante instrumento no desenvolvimento da agricultura sustentável.

A Associação MUTIRÃO, atualmente, possui um quadro social com 103 sócios, número que tende a aumentar com o novo processo de recadastramento, em andamento. Hoje, o recurso proveniente da produção na área experimental, é revertido para a manutenção da infraestrutura e para a implantação de novas instalações, além do pagamento de pessoas que realizam o manejo dos cultivos, para pagamento de salário de pessoas contratadas para prestação de serviços, como vigilante da sede e para gastos com abastecimento de água e energia elétrica. Além disso, das atividades que demandam experimentação, ainda são desenvolvidas nessa área coletiva.

A Associação MUTIRÃO desenvolveu e desenvolve debates acerca da organização social na região do Baixo Tocantins. No decorrer da pesquisa, foi notória a importância desse empreendimento no que tange ao incentivo/estímulo ao surgimento de novas formas organizacionais. Os agricultores e agricultoras familiares, formados pela associação MUTIRÃO, tem construído novos empreendimentos solidários que passam a atuar de forma articulada, como a Cooperativa Agrícola dos Empreendimentos Populares de Igarapé Miri - CAEPIM, a Cooperativa de Desenvolvimento do Município de Igarapé Miri - CODEMI, e no contexto dos direitos humanos, com foco no fortalecimento de gênero, a Associação 
Revista Tecnologia e Sociedade, Curitiba, v. 11, n. 22, 2015

Edição Especial XII Encontro Nacional de Engenharia e Desenvolvimento Social

ISSN (versão online): 1984-3526

ISSN (versão impressa): 1809-0044

de Mulheres de Igarapé Miri - ASMIM, sob os princípios da economia solidária e da agricultura sustentável.

\section{CONSIDERAÇÕES FINAIS}

Com a pesquisa foi possível concluir que além de estabelecer relações com outras entidades de assistência técnica, de pesquisa e de ensino, a Associação MUTIRÃO conseguiu articular-se, de tal modo que viabilizou o surgimento de novas formas organizacionais no município, as quais atuam em rede de empreendimentos econômicos solidários, possibilitando uma dinâmica de desenvolvimento da agricultura familiar importante no município de Igarapé Miri.

Por fim, ao organizar agricultores e agricultoras familiares, via empreendimento solidário, é possível realizar atividades de formação capazes de fortalecer o acesso a bens e serviços de uso coletivo, em diversas áreas de atuação, isto é, instituições de ensino, pesquisa e extensão, voltadas à formação em gestão de empreendimentos econômicos solidários, economia solidária, cooperativismo e associativismo, cultivo e manejo de açaí, agricultura orgânica, aquicultura e cultivo de peixe em tanque escavado, entre outras. Dentre os processos de cooperação firmadas com instituições internas e externas ao município, pode-se destacar o Sindicato dos Trabalhadores e Trabalhadoras Rurais de Igarapé Miri (STTR), Universidade Federal do Pará (UFPA), Empresa Brasileira de Pesquisa Agropecuária - Embrapa Amazônia Oriental, Associação Unidade e Cooperação para o Desenvolvimento dos Povos (UCODEP), Instituto Federal do Pará/Campus Castanhal (IFPA) e a MANITESE (União Europeia), as quais têm favorecido a melhoria do controle da produção de açaí in natura dos sócios dos empreendimentos, além de facilitar as atividades de assistência técnica e de pesquisa voltadas para a elevação da qualidade da produção, com respeito ao meio ambiente.

A Associação MUTIRÃO, em mais de duas décadas, possibilitou e possibilita à região do Baixo Tocantins avanços da organização social, destacando-se, nesse contexto de alianças, o STTR que iniciou o processo de lutas dos agricultores familiares para a melhoria das condições de vida no campo, partindo das reivindicações por acesso à terra à produção agrícola sustentável. Essa Associação 
Revista Tecnologia e Sociedade, Curitiba, v. 11, n. 22, 2015

Edição Especial XII Encontro Nacional de Engenharia e Desenvolvimento Social

ISSN (versão online): 1984-3526

ISSN (versão impressa): 1809-0044

tem conseguido buscar soluções, de forma coletiva, para os entraves da produção agrícola, em uma região onde a falta e/ou deficiência de serviços coletivos constitui uma das maiores barreiras ao desenvolvimento endógeno, cujo recurso primeiro são ações de solidariedade e cooperação entre os sujeitos da agricultura familiar ribeirinha.

\section{AGRADECIMENTO}

Agradecemos o apoio e fomento da PROPPG/IFPA, CAPES, CNPQ, PROEXT - MEC/SESU. Assim como o apoio e a cooperação dos Empreendimentos Econômicos Solidários da Amazônia Paraense.

\section{REFERÊNCIAS}

ABRAHÃO, E. L. C. R. Uma proposta de desenvolvimento sustentável nas pequenas comunidades dos Sem Terra. 2010.

ALVES, R. N. B.; MODESTO JÚNIOR, M. de S.; ANDRADE, A. C. da S. O trio da produtividade na cultura da mandioca: estudo de caso de adoção de tecnologias na região no Baixo Tocantins, Estado do Pará. In: Congresso da Associação Brasileira das Instituições de Pesquisa Tecnológica, 2008, Campina Grande. Os desníveis regionais e a inovação no Brasil: os desafios para as instituições de pesquisa tecnológica. Brasília, DF: ABIPTI, 2008. 1CD-ROM.

ARAÚJO, T. C. A. de; GODRIM, M. D.; SOUZA, V. S. A Organização Social da Agricultura Familiar do Projeto Jaíba- MG, como desafio para o desenvolvimento local sustentável. EMATER-MG, JAIBA, BRASIL. 2007. Disponível em: <http://www.sober.org.br/palestra/6/333.pdf> Acessado em: 02 de junho de 2012.

BARBOSA, C. Estado, Economia Solidária e Pedagogia. Anais do XI Congresso Luso Afro Brasileiro de Ciências Sociais - Diversidades e (des) igualdade. 2011.

BRASIL. Sociedade de Meio Ambiente Educação e Cidadania (SOMEC). Ministério do Desenvolvimento Agrário (MDA). Plano territorial de desenvolvimento rural sustentável do baixo Tocantins, Belém.

CAPORAL, F. R. e COSTABEBER, J. A. Agroecologia e Desenvolvimento Rural Sustentável: perspectivas para uma nova extensão rural. Porto Alegre: EMATER/RSASCAR, 2000.

CARDOSO, A. C.; et al. Planos diretores no Tucupi: a experiência de elaboração de planos diretores na região do Baixo Tocantins, Estado do Pará. In. Planos diretores participativos: experiências amazônicas. Belém: EDUFPA, 2007.

CORRÊA, E. de J. A. Desafios e perspectivas de ação e mobilização de trabalhadores rurais e pescadores artesanais (ribeirinhos e agroextrativistas) nas terras e águas do 
Revista Tecnologia e Sociedade, Curitiba, v. 11, n. 22, 2015

Edição Especial XII Encontro Nacional de Engenharia e Desenvolvimento Social

ISSN (versão online): 1984-3526

ISSN (versão impressa): 1809-0044

Baixo Tocantins (PA). 5ํㅡㄹ Encontro da Rede de Estudos Rurais. Belém-Pará. Disponível em:

<http://www.redesrurais.org.br/sites/default/files/Desafios\%20e\%20perspectivas\%20de\%20a \%C3\%A7\%C3\%A30\%20e\%20mobiliza\%C3\%A7\%C3\%A30\%20de\%20trabalhadores\%20rur ais\%20e\%20pescadores\%20artesanais.pdf>, 2012. Acesso em: 13 de dezembro de 2013.

COSTA, M. O. Manoel Oliveira Costa: entrevista [jan. 2014]. Entrevistador: Wagner Luiz Nascimento do Nascimento. Igarapé Miri, 2014. Entrevista concedida ao Programa Incubadora Tecnológica de Desenvolvimento e Inovação de Cooperativas e Empreendimentos Solidários do IFPA- Campus Castanhal.

CUNHA, G. C. In: Uma outra economia é possível: Paul Singer e a Economia Solidária / André Ricardo de Souza, Gabriela Cavalcanti Cunha, Regina Yoneko Dakuzaku (orgs). São Paulo. Contexto, 2003.

DAL RI, N.M.; VIEITEZ, C.G. Educação Democrática e Trabalho Associado no Movimento dos Trabalhadores Rurais Sem Terra e nas Fábricas de Autogestão. São Paulo: Ícone-Fapesp, 2008.

DAL SOGLIO, F. K. Desenvolvimento, agricultura e agroecologia: qual a ligação? In: GUERRA, G. A. D. e WAQUIL, P. D. (Organizadores). Desenvolvimento Rural Sustentável no Norte e Sul do Brasil. Belém-PA. Paka-Tatu. p. 197-226. 2013.

Gil, Antonio Carlos. Métodos e técnicas de pesquisa social. 6ª . Ed. São Paulo: Atlas, 2008.

GONZALES, R. E. Manual sobre participação e organização para a gestão local. Cali: Foro Nacional por Colômbia, 1995. 137p.

HABERMAS, J. Knowledge and human interestes. Boston: Beacon Press, 1971.

JARDIM, A. C. S e PEREIRA, V. S. Metodologia Qualitativa: é possível adequar as técnicas de coleta de dados aos contextos vividos em campo? Anais do 47을 Congresso da Sociedade Brasileira de Economia, Administração e Sociologia Rural. Porto Alegre. 2009.

KAGEYAMA, A. Desenvolvimento rural: conceitos e aplicações ao caso brasileiro. 1a ed. Porto Alegre: Editora UFRGS, 2008.

LAVILLE, J. L. e FRANÇA FILHO, G. C. Economia Solidária, uma abordagem internacional. Porto Alegre: Editora da UFRGS, 2004.

MARCUSE, H. Ruison etrevolution. Paris: Les Editions de Minuit, 1968.

MATOS, A. K. V de. Revolução verde, biotecnologia e tecnologias alternativas. Cadernos da FUCAMP, v.10, n.12, p.1-17/2010.

MODESTO JÚNIOR, M. S.; ALVES, R. N. B.; SILVA, E. S. A. Diagnóstico socioeconômico de comunidades de mandiocultores do Baixo Tocantins, Pará. In: XIV Congresso Brasileiro de Mandioca, 2011, Maceió. Mandioca: fonte de alimentos e energia. São Paulo: ABAM e Sociedade Brasileira de Mandioca, 2011.

NUNES, D. Incubação de empreendimentos de economia solidária: uma aplicação da pedagogia da participação. São Paulo: Annablume, 2009. 
OLIVEIRA, R. S. de e SANTOS, J. de L. Do pioneirismos de Rochdale ao Cooperativismo/Associativismo no Capitalismo - Uma análise do controle do estado no espaço agrário brasileiro. Revista da Casa da Geografia de Sobral (RCGS), Sobral-CE, V. 14, n. 1, p. 69-80, 2012. Disponível em: <www.uvanet.br/rcgs>.

RAZETO, L. Economia de solidariedade e organização popular. In: GADOTTI, M.; GUTIÉRREZ, F. (Orgs.). Educação comunitária e economia popular. 2. ed. São Paulo: Cortez, 1999.

SANTOS, B. de S. Produzir para viver: os caminhos da produção não capitalista. Boaventura de Sousa Santos, organizador - $2^{2}$ ed. - Rio de Janeiro: Civilização Brasileira, 2005.

SEN, A. Poverty and famines - an essay on entitlement and deprivation. Oxford: Clarendon Press, 1982. In: KAGEYAMA, A. A. Desenvolvimento Rural: Conceitos e Aplicações ao caso brasileiro. Porto Alegre. Editora da UFRGS. Ed.1. 240p. 2008.

SINGER, P. Globalização e Desemprego: diagnóstico e alternativas. São Paulo: Contexto, 1998.

SINGER, P. Introdução à Economia Solidária. 1. ed. 3. reimp. São Paulo: Perseu Abramo, 2002.

SINGER, P. Introdução a Economia Solidária. Perseu Abramo. Economia Nacional, 2002.

SINGER, P. Uma outra economia é possível: Paul Singer e a Economia Solidária. André Ricardo de

SOUZA, A. L. de. Política pública de economia solidária e desenvolvimento territorial. Boletim Mercado de Trabalho, Brasília: IPEA, n. 52, p. 63-70, 2012.

UHLMANN, G. W. Teoria Geral dos Sistemas: do atomismo ao sistemismo (uma abordagem sintética das principais vertentes contemporâneas desta Proto-Teoria. Instituto Siegen. Disponível em: <http://www.institutosiegen.com.br/documento/Teoria\%20Geral\%20dos\%20Sistema.pdf >, 2002. Acesso em: 10 de dezembro de 2013.

PLOEG J.D. Van der. O modo de produção camponês revisitado. In: A diversidade da Agricultura Familiar. S. Schneider (org.) Porto Alegre, Editora UFRGS, 2006, p. 13-54.

WANDERLEY, N. Raízes históricas do campesinato brasileiro. In: TEDESCO (Org.). Agricultura familiar: realidades e perspectivas. Passo Fundo-RS: UPF, 2001. 